\title{
Perspectiva traductora respecto de la aplicación del derecho internacional a la traducción jurídico- institucional (FR-EN): análisis de una opinión consultiva emitida por la Corte Internacional de Justicia
}

\author{
Gisella Policastro Ponce \\ CB Lingua \\ gisellapolicastro@gmail.com \\ https://dx.doi.org.10.12795/futhark.2016.il I.07
}

Fecha de recepción: 13.05.2016
Fecha de aceptación: 10.07.2016

Resumen: La realidad jurídico-institucional ha evolucionado en los últimos años hacia una perspectiva más integral, multilingüística e internacional, concretamente como consecuencia de la expansión de las relaciones internacionales y los conflictos legales que de ellas se derivan. En este contexto, la práctica de la traducción jurídico-institucional se erige como abanderada en el marco de un estudio de investigación en torno a las controversias de orden jurídico internacional. En particular, el presente trabajo parte de la realización de un proceso de traducción no oficial al español de una opinión consultiva emitida la Corte Internacional de Justicia, y únicamente disponible de forma oficial en el par de lenguas francés e inglés. El propósito del presente trabajo no es otro que destacar la labor documental necesaria para acometer la traducción de un texto de estas características, al tiempo que se pretende subrayar la imposibilidad de acceso por parte del usuario general a material relacionado con este tipo de hechos jurídicos internacionales, por encontrarse redactados únicamente en dos idiomas.

Palabras clave: traducción jurídico-institucional, derecho internacional, Corte Internacional de Justicia, documentación, investigación. 


\title{
Translator's perspective on the application of the international law to legal-institutional translation (FR-EN): analysis of an advisory opinion issued by the International Court of Justice
}

\begin{abstract}
The legal-institutional practice has evolved in recent years towards a more comprehensive, multilingual and international perspective, specifically as part of the expansion of international relations and legal conflicts arising thereof. In this context, the practice of legal-institutional translation stands as a standard-bearer in the framework of a research study on international legal disputes. In particular, this work is based on the completion of an unofficial translation process into Spanish of an advisory opinion issued by the International Court of Justice, written in French and English. The aim of this work is none other than highlighting the necessary documentary work to undertake the translation of this type of texts, while trying to underline the impossibility of access by the general user to material related to this type of international legal facts, since they are written only in two languages.
\end{abstract}

Key words: legal-institutional translation, international law, International Court of Justice, documentation, research.

Sumario: Introducción. I. La Corte Internacional de Justicia. 2. El procedimiento consultivo de la Corte. 2.I. El procedimiento consultivo. 2.2. Pronunciamiento de la opinión consultiva. 3. Análisis y explicación del procedimiento consultivo objeto de estudio. 4. Perspectiva traductora. Conclusiones.

\section{Introducción}

La disciplina de las Relaciones Internacionales constituye un ámbito de investigación altamente atractivo y complejo a la vez, debido a las diferentes variables posibles para analizar y su amplia interrelación que obliga a abordar una cuestión desde diversas perspectivas para poder obtener un análisis completo del mismo.

Es posible partir de una investigación cuantitativa o cualitativa; en ambos casos será igualmente necesario concretar de forma exhaustiva el argumento central en torno al que va a girar nuestro proyecto de investigación. El ámbito jurídico-institucional de las relaciones internacionales es inmensamente amplio, por tanto, ha sido necesario focalizar e identificar las cuestiones de mayor interés, tanto personal como general, y optar por un campo concreto. 
En primera instancia, se ha concretado el planteamiento en torno al concepto de la seguridad internacional en el ámbito de su aplicación: los Tribunales internacionales y su jurisprudencia. Atendiendo al profesor Diez-Picazo (1979) la jurisprudencia «significa, ante todo, un complejo de afirmaciones y decisiones pronunciadas en sus sentencias por los órganos jurisdiccionales del Estado y contenidas en ellas. (...) más concretamente, por el alto órgano jurisdiccional del estado, el Tribunal Supremo». Nuestro objetivo comienza por analizar las diferentes fuentes de información jurídica de los tribunales supranacionales, que se caracterizan por ostentar mayor poder de decisión sobre lo Estados miembros y respecto de los individuos de cada Estado. Existen en la comunidad internacional una amplia variedad de órganos jurisdiccionales destinados a resolver los conflictos regidos por el Derecho internacional.

En este nivel, nos percatamos que nuestro enfoque inicial sigue siendo demasiado amplio, pues en el ámbito internacional podemos identificar numerosos Tribunales Supranacionales encargados de velar por la seguridad internacional, de uniformizar el derecho y la jurisprudencia nacional e internacional, bajo la primacía del derecho internacional, en tal sentido, sobre la Constitución nacional de cada país: Tribunales creados bajo los auspicios de las Naciones Unidas de forma permanente, como la Corte Internacional de Justicia, que desempeña la función judicial de esta dicha organización internacional, y la Corte Penal Internacional, encargada de los delitos muy graves de ámbito internacional, tales como crímenes de guerra, genocidio y crímenes contra la humanidad; y de forma no permanente, como el Tribunal Penal Internacional para la antigua Yugoslavia y el Tribunal Penal Internacional para Ruanda; el Tribunal Europeo de Derechos Humanos, que es la máxima autoridad judicial de Europa que vela por la garantía de los derechos humanos y libertades fundamentales; el Tribunal de Justicia de las Comunidades Europeas, facultado para garantizar la correcta interpretación y aplicación de la legislación de la Unión Europea en todos los Estados miembro; o el Tribunal Permanente de Arbitraje, que tiene como propósito resolver controversias internacionales a través de la aplicación de una jurisdicción arbitral, entre otros.

Ante la gran variedad de organismos jurídicos mencionados, se exige nuevamente reducir el foco de análisis a un nivel más concreto. De esta forma surge esta comunicación, con el intento de conseguir un acercamiento, a través de la traducción, al conocimiento por parte del usuario general del principal organismo judicial del mundo, la Corte Internacional de Justicia.

El presente trabajo consiste, por tanto, en la traducción de un documento oficial de la Corte Internacional de Justicia de las Naciones Unidas redactado en inglés y francés, con fecha de 22 de julio de 2010. El documento es una opinión consultiva emitida por el órgano principal de la Organización de Naciones Unidas, titulado "Conformidad con el derecho internacional de la declaración de independencia 
de Kosovo" (su versión original en inglés "Accordance with international law of the unilateral declaration of Independence in respect of Kosovo" (Request for Advisory Opinion) y en francés "Conformité au droit international de la déclaration unilatérale d'indépendance relative au Kosovo (requête pour avis consultatif)".

La documentación especializada y traductológica debe ser el paso inicial de todo proceso de traducción, de manera que se adquiera toda la información fiable y específica sobre la temática y la especialidad en la que se encuadra el texto que va a ser traducido, junto con un compendio de obras de referencia sobre la tipología de traducción especializada que facilite la resolución posterior de problemas terminológicos, cognitivos, interpretativos y traslativos. A tal efecto, se procede a facilitar la información documental necesaria que se ha utilizado para el desarrollo de nuestro trabajo.

\section{La Corte Internacional de Justicia}

La Corte Internacional de Justicia es el principal órgano judicial de la Organización de Naciones Unidas (ONU, por sus siglas en español), con sede en el Palacio de la Paz, La Haya (Países Bajos), siendo por tanto el único órgano de la ONU que no tiene su sede en Nueva York. Sus orígenes se remontan a junio de 1945, fecha en la que fue establecida por la Carta de las Naciones Unidas, aunque comenzó a ejercer sus funciones el 18 de abril de 1946. Es sucesora de la Corte Permanente de Justicia Internacional (CPJI, por sus siglas en inglés), creada en 1922 por la Sociedad de Naciones y disuelta tras la resolución de la Segunda Guerra Mundial. La Corte Internacional de Justicia heredó los Estatutos y la jurisprudencia y las tradiciones de la CPJI.

El documento fundacional por el que se rige es el Estatuto de la Corte Internacional de Justicia y es parte integrante de la Carta de Naciones Unidas. En consecuencia, todos los Estados miembro de la ONU reconocen automáticamente la existencia de la Corte y pueden recurrir a ella haciendo uso de sus servicios. De conformidad con lo establecido en dichos Estatutos, la Corte desempeña una doble misión: el arreglo conforme al Derecho Internacional de controversias y disputas entre Estados que le sean sometidas por los mismos y la emisión de dictámenes sobre cuestiones jurídicas planteadas por la Asamblea General, el Consejo General u otros órganos o agencias de Naciones Unidas que hayan sido autorizados al respecto, en este caso hablamos de procedimientos consultivos.

Como hemos señalado, la primera misión de la Corte de dirimir asuntos contenciosos entre estados representa el $80 \%$ de su actividad y estos versan cada vez más frecuentemente sobre derecho internacional humanitario, derecho medioambiental, el uso de la fuerza armada y la responsabilidad de los estados. La 
jurisdicción de la Corte general, por tanto, puede tratar cualquier problema de derecho internacional. Todos los Estados miembro de las Naciones Unidas pueden iniciar un procedimiento contencioso ante la Corte. Otros estados también pueden hacerlo si se cumplen cierta condiciones; en este sentido la jurisdicción de la Corte es universal.

Cabe mencionar que los estados son soberanos, tienen libertad para elegir cómo quieren resolver sus disputas. La Corte solo puede tratar un asunto si los estados involucrados consienten libremente en presentarlo ante la misma. Todos los fallos de la corte son definitivos y sin posibilidad de apelación. Conviene subrayar que al presentarse libremente ante la Corte, los Estados litigantes se comprometen igualmente a respetar sus decisiones que son vinculantes para las partes. En virtud del artículo 94 de la Carta, si un estado se niega a respetar una sentencia de la Corte, el Estado opuesto puede recurrir al Consejo General de las Naciones puede hacer una recomendación 0 tomar las medidas necesarias para ejecutar la sentencia. Dada la gran autoridad legal, moral y diplomática de las decisiones de la Corte es muy inusual que esto ocurra.

La segunda misión de la $\mathrm{ClJ}$, como hemos señalado anteriormente, es responder cuestiones jurídicas planteadas por determinados organismos $\circ$ instituciones de la ONU: este procedimiento culmina en las denominadas opiniones consultivas o dictámenes, la mayoría solicitados por la Asamblea General. A diferencia de las sentencias, los dictámenes de la $\mathrm{ClJ}$ carecen de carácter vinculante y corresponde a los órganos e instituciones especializadas de las Naciones Unidas que los han solicitado darle el curso que consideren adecuado. En cualquier caso, la autoridad jurídica y moral de la Corte confiere a sus opiniones un gran peso. El hecho se tomen en consideración por parte de los estados y las organizaciones internacionales en su práctica jurídica contribuye al desarrollo del derecho internacional. Sus decisiones tienen una repercusión que va más allá de los estados y las organizaciones directamente implicados en los casos. En numerosas ocasiones, la Corte ha ayudado a distender crisis, normalizar relaciones entre estados y a reactivar negociaciones estancadas, tanto mediante el arreglo judicial de controversias como declarando el derecho aplicable a una cuestión concreta.

La Corte cuenta con quince magistrados elegidos por la Asamblea General y el Consejo de Seguridad de Naciones Unidas, en votaciones independientes, por un periodo de nueve años. Procede cada tres años a la renovación de una tercera parte de sus magistrados, siendo posible su reelección. Los magistrados no representan a sus respectivos Gobiernos, sino que son magistrados independientes.

Los idiomas oficiales de la Corte son el inglés y el francés, por consiguiente, todo lo escrito o dicho en un idioma, es traducido al otro. 


\title{
2. El procedimiento consultivo de la Corte
}

De conformidad con el Artículo 38 de su Estatuto, la Corte, al decidir las controversias que se le sometan, aplica: las convenciones y tratados internacionales, la costumbre internacional, los principios generales del derecho, $y$, subsidiariamente, las decisiones judiciales.

Sólo los Estados tienen derecho a comparecer ante la Corte, por tanto las organizaciones internacionales públicas no pueden ser partes como tales en ningún asunto contencioso o litigio propiamente dicho. En cambio, los órganos e instituciones especializadas de las Naciones Unidas, exclusivamente, tienen a su disposición un procedimiento especial llamado procedimiento consultivo. Según el Artículo 96 de la Carta de las Naciones Unidas:

\begin{abstract}
« I. La Asamblea General o el Consejo de Seguridad podrán solicitar de la Corte Internacional de Justicia que emita una opinión consultiva sobre cualquier cuestión jurídica. Los otros órganos de las Naciones Unidas y los organismos especializados que en cualquier momento sean autorizados para ello por la Asamblea General, podrán igualmente solicitar de la Corte opiniones consultivas sobre cuestiones jurídicas que surjan dentro de la esfera de sus actividades».
\end{abstract}

En el ejercicio de su función consultiva, la Corte debe permanecer fiel a las exigencias de su carácter judicial y no separarse de las normas esenciales que regulan su actividad como tribunal (Espósito, 201 I:I43). Ésta ostenta la facultad discrecional de negarse a contestar a una solicitud de opinión consultiva cuando el contestarla supondría la oposición a tales exigencias y normas aunque, en principio, no debe negarse a pronunciarse sobre una solicitud de opinión consultiva (Soroeta, 20I2) en muchas ocasiones ha debido cuestionarse si realmente era competente, si el asunto planteado era realmente jurídico, si procedía contestar, etc.

El procedimiento consultivo sugiere ciertas similitudes con el procedimiento contencioso (Espósito, 1995) si bien presenta rasgos distintos debido a la naturaleza y el objeto particular de la función consultiva. Por lo demás, el espíritu de la Corte se inspira en las disposiciones del Estatuto y del Reglamento sobre el procedimiento contencioso en la medida que se estime que puedan ser aplicables (Capítulo IV, de la Carta de las Naciones Unidas) ${ }^{1}$.

I (N. d. A.) Capítulo 4, Carta de las Naciones Unidas: “Artículo 65 I. La Corte podrá emitir opiniones consultivas respecto de cualquier cuestión jurídica, a solicitud de cualquier organismo autorizado para ello por la Carta de las Naciones Unidas, o de acuerdo con las disposiciones de la misma. 2. Las cuestiones sobre las cuales se solicite opinión consultiva serán expuestas a la Corte mediante solicitud escrita, en que se formule en términos precisos la cuestión respecto de la cual se haga la consulta. Con dicha solicitud se acompañarán todos los documentos que puedan arrojar luz sobre la cuestión. Artículo 66. I. Tan pronto como se reciba una solicitud de opinión consultiva, el Secretario la notificará a todos los Estados que tengan derecho a comparecer ante la Corte. 2. El Secretario notificará también, 


\section{I. El procedimiento consultivo}

Un procedimiento consultivo se inicia ante la Corte mediante una solicitud de opinión consultiva. El órgano u organismo capacitado para ello por la Carta de las Naciones Unidas aprueba, después de discutirla, la cuestión que ha de someterse a la Corte y la incorpora a una resolución o decisión. En un plazo de dos semanas, la solicitud se presenta ante la Corte mediante una carta del Secretario General de las Naciones Unidas o del Director o Secretario General del órgano solicitante. Tan pronto como se reciba la solicitud, el secretario la notificará a todos los Estados afectados a comparecer ante la Corte.

A fin de aclarar la cuestión que le ha sido encomendada, la Corte puede disponer que se celebre un procedimiento escrito y/u oral, aspecto que recuerda al procedimiento contencioso (Espósito, 1995). En primer lugar se lleva a cabo el procedimiento escrito, más rápido pero igual de flexible que el procedimiento contencioso entre Estados, pudiéndose incluso prescindirse del mismo en caso de urgencia. El Presidente fija, mediante una providencia, el plazo dentro del cual los Estados y organizaciones escogidos pueden presentar, si así lo desean, sus exposiciones o alegaciones escritas.

Las exposiciones se dirigen al secretario de la Corte quien se encarga de reunirlas y solicitar su traducción, en caso necesario, para uso de la Corte, y de comunicarlas a los jueces y a todos los Estados y organizaciones que hayan presentado las suyas. Al propio tiempo se invita a dichos Estados a facilitar información oral en audiencia pública cuya fecha es fijada por el Presidente. Las exposiciones se consideran confidenciales pero pueden ser puestas a disposición del público antes de que empiece el procedimiento oral.

mediante comunicación especial y directa a todo Estado con derecho a comparecer ante la Corte, y a toda organización internacional que a juicio de la Corte, o de su Presidente si la Corte no estuviere reunida, puedan suministrar alguna información sobre la cuestión, que la Corte estará lista para recibir exposiciones escritas dentro del término que fijará el Presidente, o para oír en audiencia pública que se celebrará al efecto, exposiciones orales relativas a dicha cuestión. 3. Cualquier Estado con derecho a comparecer ante la Corte que no haya recibido la comunicación especial mencionada en el párrafo 2 de este Artículo, podrá expresar su deseo de presentar una exposición escrita o de ser oído y la Corte decidirá. 4. Se permitirá a los Estados y a las organizaciones que hayan presentado exposiciones escritas $\mathrm{u}$ orales, o de ambas clases, discutir las exposiciones presentadas por otros Estados u organizaciones en la forma, en la extensión y dentro del término que en cada caso fije la Corte, o su Presidente si la Corte no estuviere reunida. Con tal fin, el Secretario comunicará oportunamente tales exposiciones escritas a los Estados y organizaciones que hayan presentado las suyas. Artículo 67. La Corte pronunciará sus opiniones consultivas en audiencia pública, previa notificación al Secretario General de las Naciones Unidas y a los representantes de los Miembros de las Naciones Unidas, de los otros Estados y de las organizaciones internacionales directamente interesados. Artículo 68. En el ejercicio de sus funciones consultivas, la Corte se guiará además por las disposiciones de este Estatuto que rijan en materia contenciosa, en la medida en que la propia Corte las considere aplicables. 
Cuando se inicia un procedimiento oral, normalmente se celebra dos meses después de la presentación de las exposiciones escritas y no toman en general más de siete audiencias. La participación de la organización solicitante en el procedimiento reviste doble carácter obligatorio y facultativo.

\subsection{Pronunciamiento de la opinión consultiva}

Excepto en el caso en que la organización solicitante retire su solicitud, el procedimiento consultivo concluye con el pronunciamiento de la opinión. Cabe señalar que las opiniones consultivas se pronuncian más rápidamente que los fallos y suelen ser un poco más breves. Se redactan siguiendo la misma técnica de deliberaciones que las empleadas para el fallo, y como éste se divide en introducción, motivos y parte dispositiva:

- En la introducción, se consignan los nombres de los jueces y de los representantes de las partes, un resumen del procedimiento sin comentario alguno y las conclusiones de las partes.

- Los motivos comienzan frecuentemente considerando si la Corte es competente y si debe acceder o no a la solicitud. Seguidamente, se exponen en detalle los hechos y fundamentos de derecho considerados por la Corte y se examinan con cuidado y ecuanimidad los argumentos de las partes.

- La parte dispositiva está introducida por las mismas fórmulas, del tipo "por estas razones", o "por estos motivos". A continuación, se presenta la decisión propiamente dicha de la Corte.

La opinión consultiva va acompañada de opiniones separadas o disidentes. Antes de definir a estos dos tipos de opiniones, es necesario explicar brevemente la importancia de las mismas en una opinión consultiva. El principio del secreto de las deliberaciones tiene por consecuencia que los fallos indican únicamente el número de jueces que han votado a favor y en contra de cada uno de los puntos de la parte dispositiva, sin mencionar quién ha votado de una forma u otra. Por otro lado, se admite que los miembros de la Corte publiquen a continuación del fallo u opinión sus propias opiniones. Estas opiniones, como se ha señalado, pueden adoptar diversas formas:

- Opiniones disidentes: expresan las decisiones por las que un juez está en desacuerdo con la decisión de la Corte, es decir, por qué votó en contra.

- Opiniones separadas: emanan de un juez que ha votado a favor de las disposiciones de la Corte, pero está en desacuerdo con todos o parte de los motivos de la Corte o ha sido impulsado a votar a favor por razones distintas o adicionales. 
La opinión consultiva se redacta e imprime en los dos idiomas oficiales y se envía a los Estados a los cuales está abierta la Corte.

\section{Análisis y explicación del procedimiento consultivo objeto de estudio}

La solicitud de opinión consultiva objeto de estudio fue presentada ante la Corte Internacional de Justicia por los representantes del pueblo kosovar, en virtud del Artículo 65 del Estatuto de la Corte, para que respondiera a la cuestión sobre si "iSe ajusta al derecho internacional la declaración unilateral de independencia formulada por las instituciones provisionales de autogobierno de Kosovo?".

Se ha realizado un análisis exhaustivo sobre el documento oficial de opinión consultiva traducido en este trabajo del inglés y francés al español, siguiendo el modelo de procedimiento consultivo explicado en el apartado anterior. Por tanto, el análisis quedará estructurado en tres partes: introducción, motivos y parte dispositiva.

En primer lugar, y de forma particular, este documento comienza con una tabla de contenidos, que precede a la introducción propia de todo procedimiento consultivo, que estructura el desarrollo del procedimiento, acompañada de una presentación general del caso, resaltado en cursiva.

A continuación, se presenta la introducción correspondiente, que presenta de forma resumida el procedimiento escrito y oral y las conclusiones de las partes. Después de presentar los antecedentes fácticos, que ya se han presentado en este trabajo, la Corte pasa a analizar la conformidad del derecho internacional de la declaración de independencia de Kosovo. A continuación, comienzan a enumerarse los diferentes párrafos de la opinión consultiva, que constituyen, en su mayoría, los motivos.

Seguidamente, la Corte pasa a presentar su opinión en la parte dispositiva: "Por diez votos contra cuatro, opina que la declaración de independencia de Kosovo aprobada el 17 de febrero de 2008 no violó el derecho internacional".

La cuestión planteada a la Corte implicaba en sí misma un acto controvertido, tratándose de una declaración de independencia considerada nula y sin efecto por parte de la Asamblea Nacional de Serbia y declarada acto ilegal por la Corte Constitucional de la República de Serbia, argumentando que no era compatible con los estatutos de Naciones Unidas, con la Constitución de Serbia, con la Declaración de Helsinki y con la Resolución 1244 de Naciones Unidas, además de no ser reconocida por 37 países de la esfera internacional.

En torno a la declaración de independencia de Kosovo se generó una importante disputa sobre su encaje con la legalidad vigente y sobre si este acto 
podría ser considerado un precedente para otras regiones secesionistas europeas, lo que supuso un rechazo de la opinión consultiva emitida por la Corte Internacional de Justicia por gran parte de los países que se negaban a reconocer la independencia de Kosovo.

\section{Perspectiva traductora}

Este trabajo se enmarca dentro de la especialidad de traducción institucional, que hace referencia a las traducciones realizadas, tanto a nivel nacional como internacional, por instituciones u organismos internacionales de manera conjunta por un grupo colectivo de traductores y produce una gran diversidad de textos jurídicos (Montolío Durán, 20I2).

Otro de los aspectos destacables derivados de la presente comunicación hace referencia al planteamiento de que los trabajos de traducción institucional deben atenerse a patrones formales predeterminados, adaptarse al lenguaje jurídico y político administrativo y guardar una coherencia léxica con el resto de los textos producidos por las instituciones internacionales.

Siguiendo a Martín Ruano (20I2), somos conscientes de que, a pesar de encontrarnos en la era de la globalización y expansión de la comunicación, existe una gran desigualdad entre las lenguas en los contextos institucionales, puesto que no todas gozan de los mismos beneficios. El caso que nos ocupa es muestra de ello, en tanto que los documentos originales se encontraban disponibles solamente en dos lenguas, inglés y francés, así como toda la documentación relacionada con el caso, con la desventaja en algunos casos de que no eran textos originales, sino traducciones al inglés y el francés desde otros idiomas.

El núcleo más destacado de este proyecto se basa la combinación entre un contenido especializado, riguroso y académico y un público meta que se presupone con un conocimiento básico del trabajo que se presenta, lo que otorga mayor complejidad y abstracción. Como ya hemos mencionado, el proceso de documentación es el eje central del presente artículo consistente en recuperar la información procedente de las fuentes primarias y secundarias recogidas en las fuentes de administración de justicia internacional respecto de los derechos internacionales y la jurisprudencia de la propia Corte Internacional de Justicia. Para llevar a cabo esta tarea fue necesaria la compilación de documentación especializada, de carácter terminológico y de carácter fraseológico. 
En el ámbito jurídico-institucional en el que se enmarca esta traducción, fue necesario consultar textos doctrinales, como manuales de derecho comparado, textos normativos de derecho internacional; obras de referencia sobre la organización y misión de la Corte Internacional de Justicia; textos judiciales citados en la propia opinión consultiva, entre otros. Además, fue necesario también llevar a cabo un proceso documentación específico sobre el caso de la independencia de Kosovo, antecedentes y datos históricos que se encontraron en libros de historia y, principalmente, en artículos y páginas web especializadas sobre historia, política, cultura y actualidad.

Para solucionar las cuestiones relativas a la terminología especializada, se recurrió al uso de diccionarios monolingües y bilingües, tanto generales como especializados en terminología jurídica; diccionarios terminológicos sobre traducción jurídica y traducción institucional; glosarios terminológicos, entre ellos el glosario que ofrece la ONU en su página web.

Por último, respecto al carácter fraseológico de la traducción jurídicoinstitucional resulta fundamental el respeto de la forma, el uso del lenguaje específico común (denominaciones de órganos, expresiones acuñadas, terminología pertinente) $\circ$ la exactitud de las citas a documentos jurídicos (títulos de documentos, sentencias, cartas, normativas, reglamentos).

El universo jurídico constituye un arduo proceso de interpretación, marcado por la particularidad y complejidad de cada ordenamiento jurídico, que hace de este lenguaje uno de los más oscuros y difíciles de abordar. La combinación entre diferentes estructuras jurídicas que presenta una falta de correspondencia biunívoca entre las lenguas, unida a la propia dificultad que el lenguaje jurídico entraña, como consecuencia de su reiteración terminológica y la compleja terminología de sus textos, dificultan los intentos por hacer del lenguaje jurídico un lenguaje transparente y comprensible para todos.

\section{Conclusiones}

La Corte se ha calificado a sí misma como un órgano de derecho internacional, que rinde justicia dentro de los límites que le han sido asignados. No existe hoy en el mundo ningún otro órgano judicial que tenga la misma capacidad para tratar los problemas de la comunidad internacional en su conjunto y que ofrezca a los Estados tal variedad de recursos para defender la primacía del derecho internacional. A través de sus sentencias, autos y opiniones la $\mathrm{ClJ}$ ayuda a las Naciones Unidas a alcanzar sus principios fundamentales, que son el mantenimiento y la consolidación de la paz y seguridad internacionales. 
Tras someter a análisis traductológico la opinión consultiva emitida por la ClJ sobre la independencia de Kosovo, concluimos que en la actividad documental es el eje fundamental de este tipo de trabajos de traducción, al ser un soporte indispensable para conocer en profundidad el caso, resolver las dificultades de correspondencia entre diferentes realidades jurídicas, conceptuales y terminológicas que el texto planteaba.

\section{Referencias bibliográficas}

ÁlvareZ, C. (20II). Estudio del lenguaje de especialidad económico: el lenguaje del comercio internacional. Entreculturas. Disponible en: http://www.entreculturas.uma.es/n3pdf/articulol5.pdf.

ANDÚJAR, G (2007). Técnicas de traducción jurada: un análisis contrastivo francéscastellano. Sendebar. Revista de la Facultad de Traducción e Interpretación. Disponible http://revistaseug.ugr.es/index.php/sendebar/article/view/687/779. (20II). Los elementos paratextuales en la traducción jurada de documentos académicos. RAEL: revista electrónica de lingüística aplicada. Disponible https://repositori.upf.edu/bitstream/handle/I0230/23। I2/andujar_rael.pdf?s equence $=\mid$ \&isAllowed $=y$.

BorjA, A. (2004). La investigación en traducción jurídica. En García Peinado y Ortega Arjonilla (dirs.) Panorama actual de la investigación en traducción e interpretación. Granada: Atrio. Disponible en: http://www.gentt.uji.es/Publicacions/Borja La investigacion_en T].pdf.

DieZ-PICAZO, L. (1979). Estudios sobre la jurisprudencia civil. Madrid: Experiencias jurídicas.

EsPósITO, C. (1995). La jurisdicción consultiva de la Corte Internacional de Justicia: su valor en la determinación del Derecho internacional y en la solución pacífica de controversias. Madrid: Universidad Autónoma de Madrid. Disponible en http://hdl.handle.net//0486/4553.

- (20II). El discreto ejercicio de la función consultiva de la Corte Internacional de Justicia en el asunto de Kosovo. REDI. Disponible en: http://www.revista-redi.es/es/articulos/el-discreto-ejercicio-de-la-funcionconsultiva-de-la-corte-internacional-de-justicia-en-el-asunto-kosovo/

SOROETA, J. (20I3). La opinión consultiva de la Corte Internacional de Justicia sobre Kosovo de 22 de julio de 2010: Una interpretación judicial sui generis para un caso que no lo es. Aplicabilidad de la cláusula de salvaguardia de la Resolución 2625 (XXV) o de la "secesión como remedio". Revista electrónica de estudios internacionales (REEI). Disponible en: http://www.reei.org/index.php/revista/num25/articulos/opinion-consultiva- 
corte-internacional-justicia-sobre-kosovo-22-julio-2010-unainterpretacion-judicial-sui-generis-para-caso-lo-es-aplicabilidad-clausulasalvaguardia-resolucion-2625-xxv-secesion-como-remedio.

Martín, M. R. (20I2). Traducción e identidad(es): asimetrías, conflictos y posibilidades. En: Alonso, I.; BAIGORRI, J.; CAMPBELL, H. (eds.) Ensayos sobre traducción jurídica e institucional/Essays on Legal and Institutional Translation. Granada: Comares.

Martínez, A. B., ORTeGA, E. (2006). Recursos bibliográficos sobre traducción, redacción y terminología en los ámbitos jurídico y económico (español, francés e inglés)". TRANS - Revista de Traductología. Disponible en: http://www.revistas.uma.es/index.php/trans/article/view/l094.

MONTOLío, E. (2012). La situación del discurso jurídico escrito español. Estado de la cuestión y algunas propuestas de mejora. En MONTOLío, E. (ed.): Hacia la modernización del discurso jurídico, Barcelona: Universitat de Barcelona.

NACIONES UNIDAS. (1945). Carta de las Naciones Unidas. Disponible en: http://www.un.org/es/charter-united-nations/. (1948). Declaración Universal de Derechos Humanos. Disponible en: http://www.un.org/es/documents/udhrl.

ORTS, M. A. (2005). Semejanzas y diferencias léxicas en el lenguaje contractual en inglés $y$ en castellano. Ibérica. Disponible en: http://www.aelfe.org/documents/03-lb/0-Orts.pdf. 
